\title{
Experimental study for the process of the borehole thermal reaming by means of the angular plasmatron
}

\author{
Oleksii Voloshyn ${ }^{1, *}$, Iryna Potapchuk ${ }^{1}$, Volodymyr Yemelianenko ${ }^{1}$, Mykola Zhovtonoha ${ }^{2}$, \\ and Vitalii Pertsevyi ${ }^{2}$ \\ ${ }^{1}$ Institute of Geotechnical Mechanics named by N. Poljakov of National Academy of Sciences of \\ Ukraine, 49005, Dnipro, Simferopolska Str., 2a, Ukraine \\ ${ }^{2}$ Dnipro National University of Railway Transport named after Academician V. Lazaryan, 49010 \\ Dnipro, Lazaryana Str., 2, Ukraine
}

\begin{abstract}
Full-scale experimental study of the rock spallation by means of plasma jets is carried out. The aim of the experimental study was the measurement of the thermal power of plasma, weight of the rock spalls and duration of the plasma jets influence on the borehole surface. For the weight measurement of the rock spalls VT-200 analytical balance was used. In experimental study plasma jets flow out directly into the borehole of the granite block. The borehole and nozzles parameters of the plasmatron are complied with geometrical similarity. Experimental data are processed in the form of the energy consumption dependence of the thermal reaming of the borehole from the duration of the thermal treatment of the borehole surface. The results of the study could be applied to the borehole drilling processes.
\end{abstract}

\section{Introduction}

At present time problems related to the spallation and destruction of materials are of most interest [1-4].

In a modern mining thermal spallation reaming of the rock is used for a quarry extraction, forming of cavities and stimulation of oil and gas boreholes [5-8].

The processes of the thermal reaming are used in other branches of engineering and industry.

In particular, a task of mathematical models development of the thermal reaming and determination of term of safe exploitation of thermal barrier coatings that are used for manufacturing of turbine blades, combustion chambers of turbo-engines, pipes of the boilers and other equipment is urgent [9-11].

Application of theoretical and experimental investigations of thermal destruction of the rock by spallation is useful also for problems solving in aerospace industry, in particular, for mathematical modeling of ablation processes during supersonic plasma jet interaction with the surface of solid bodies [12].

*Corresponding author: OIVoloshyn1951@nas.gov.ua 
The relevance of application of thermal methods for rock destruction is based on the wide range of facilities for realization of the heating or cooling processes of rock.

Forms of thermal influence on the rock have the unified physical basis, namely, change of power connections potential [13].

Tensions of thermal expansion of rock minerals are proportional to the thermal expansion coefficient of minerals, Young's modulus and heating temperature.

Since Young's modulus and thermal expansion coefficient of rock minerals take different values, while heating inside the rock minerals besides tensions, predefined by the emergence of temperature gradient, the structural thermal tensions appear, that reach maximal values on the edges of mineral grains.

Therefore most of thermal rock destruction products detach from the rock mass along the grain edges of minerals [14].

In the cases of application of thermal methods of rock destruction the destruction products detach from the rock mass under the influence of the shear and tensile thermal stresses.

It is known that the strength limit for shearing and stretching is approximately 710 times less than the strength limit for the compression.

Therefore a thermal method of rock destruction is the most energy saving method of destruction [15].

While temperature increasing in a heating area along with the strength and aggregate hardness decreasing there is a reduction of rock fragility emerges that allows to use the thermal methods of rock destruction effectively not only in the processes of the borehole drilling but also in the processes of the boreholes reaming [16-18].

Most effective amid the processes of the borehole reaming are the thermal ones, in particular with application of the gas jet heating of rock with usage of arc electrical discharge.

Plasma burners have some advantages:

- widened adjustment range of thermal parameters and concentration of the jet power [19];

- diminished amount of hazardous gases emission [19];

- simplified system of the burners automation [20].

- fissure propagation at significant depth of the rocks in the process of their thermal destruction [20];

- higher values of the heat transfer coefficient and specific heat flux from the heattransfer medium to the borehole surface [21].

It should be noted that efficiency of thermal fragile rock destruction increases due to rock hardness augmentation and expenditures of this process realization tend to diminish.

The highest efficiency of thermal method for rock destruction is reached in the borehole reaming process in a monolithic enough and well-drillable rock mass.

A common feature of the known options of technical decisions related to the application of the thermal tools with an arc electrical discharge for rock destruction is a stream of low temperature plasma that outflows from one or several nozzles in parallel or at an angle to the borehole axis.

Majority of the known experimental investigations concern the determination of time and temperature values of rock destruction.

In particular, in reference [22] for slot cutting plasma burner was used with thermophysical parameters of the torch as follows: efficiency temperature of the plasma torch $4000-7000{ }^{\circ} \mathrm{C}$; maximal specific heat flux $1.2 \cdot 10^{7} \mathrm{~W} / \mathrm{m}^{2}$; heat transfer coefficient - up to $14 \mathrm{MW} /\left(\mathrm{m}^{2} \cdot \mathrm{K}\right)$.

The effect of the plasma burner application in the process of the thermal drilling was the formation of cracks up to $0.1 \mathrm{~mm}$, that spread to considerable distance $(1.2 \mathrm{~cm}$ and further) 
from the drilling channel.

In the reference [23] plasmatrons with the power within the range $25-30 \mathrm{~kW}$ were used for the heating of the borehole surface. Distance from the nozzle to the borehole surface was $20 \mathrm{~mm}$, heat flux of the plasma jet was within the range $(5.82-11.64) \cdot 10^{7} \mathrm{~W} / \mathrm{m}^{2}$, temperature of the plasma jet was $4000 \mathrm{~K}$.

In the reference [24] experimental study of the reaming process by means of plasmatron was executed for the borehole with initial diameter $60 \mathrm{~mm}$. Plasmatron power was within the range $30-65 \mathrm{~kW}$. Air consumption is within the range $0.005-0.010 \mathrm{~kg} / \mathrm{s}$. Mass-averaged temperature of the plasma flow was within the range 3000-4000 K. Air pressure at the level of $0.35 \mathrm{MPa}$ provides the supersonic outflow mode of the plasma. Specific heat flux at the borehole surface was within the range $1.4-2.6410^{4} \mathrm{~kW} / \mathrm{m}^{2}$.

Velocity of the reaming device inside the borehole was in the range of 3-8 m/hr.

Aiming the reduction of the concentration of nitrogen oxides in gases released from plasma jet and increasing of efficiency of energy transmission to rock, it is suggested to apply an open electric arc [25].

It will allow to intensify a heat exchange by radiation, as a temperature on the arc axis will reach 5000-10000 K.

In the spectrum of arc radiation approximately $50 \%$ constitutes infrared radiation.

In the process of experimental investigation electric current of arc changed within the range of 90-150 A, air consumption was within the range of $1-3 \mathrm{~m}^{3} / \mathrm{hr}$, specific heat flux was $1 \mathrm{MW} / \mathrm{m}^{2}$.

A method of the application of combustion chamber that provides increasing of thermal efficiency of plasma jet and reduction of nitrogen oxides content in a jet is known [26].

Parameters of the plasmatron for this purpose are shown in the Table 1.

Table 1. Parameters of the plasmatron.

\begin{tabular}{|c|c|}
\hline Parameter & Value \\
\hline Power, $\mathrm{kW}$ & $1200-1600$ \\
\hline Discharge power, $\mathrm{kW}$ & $300-600$ \\
\hline Air consumption, $\mathrm{kg} / \mathrm{s}$ & $0.3-0.4$ \\
\hline Mass-averaged jet temperature, $\mathrm{K}$ & $2500-2900$ \\
\hline Mass-averaged velocity of the jet outflow, $\mathrm{m} / \mathrm{s}$ & $1000-1500$ \\
\hline Thermal efficiency & $0.7-0.8$ \\
\hline
\end{tabular}

The results of experimental investigation of plasma method of thermal borehole reaming from an initial diameter $100 \mathrm{~mm}$ to $500 \mathrm{~mm}$ on a depth up to $70 \mathrm{~m}$ is known [27].

The operating parameters of plasmatron are shown in the Table 2.

Table 2. Parameters of the plasmatron.

\begin{tabular}{|c|c|}
\hline Parameter & Value \\
\hline Power, $\mathrm{kW}$ & $140-180$ \\
\hline Compressed air pressure, $\mathrm{MPa}$ & $0.4-0.5$ \\
\hline Air consumption, $\mathrm{m}^{3} / \mathrm{s}$ & $0.04-0.06$ \\
\hline Water pressure for cooling of electrodes, $\mathrm{MPa}$ & $0.8-1.0$ \\
\hline Water consumption, $\mathrm{m}^{3} / \mathrm{s}$ & 0.65 \\
\hline
\end{tabular}

Parameters of the thermal reaming of the borehole by the case of quartzites are shown in the Table 3.

Results of the known experimental study [28] of the boreholes thermal reaming by means of plasmatron are presented in the Table 4.

Accordingly to the experimental study [29] in case jets of combustion products move parallel down the borehole axis, heat transfer coefficient is within the range 102- 
$103 \mathrm{~W} /\left(\mathrm{m}^{2} \mathrm{~K}\right)$, period of the spalls detachment is within the range $1-100 \mathrm{~s}$, their thickness is within the range $0.5-0.7 \mathrm{~mm}$.

Table 3. Parameters of the thermal reaming.

\begin{tabular}{|c|c|c|c|c|}
\hline $\begin{array}{c}\text { Borehole } \\
\text { diameter after } \\
\text { the thermal } \\
\text { reaming, } \mathrm{mm}\end{array}$ & $\begin{array}{c}\text { Duration of } \\
\text { the thermal } \\
\text { reaming } \\
\text { process, } \mathrm{hr}\end{array}$ & $\begin{array}{c}\text { Productivity of } \\
\text { the thermal } \\
\text { reaming process, } \\
\mathrm{m} / \mathrm{hr}\end{array}$ & $\begin{array}{c}\text { Plasmatron } \\
\text { power, } \mathrm{kW}\end{array}$ & $\begin{array}{c}\text { Air } \\
\text { consumption, } \\
\mathrm{m}^{3} / \mathrm{min}\end{array}$ \\
\hline 350 & 53 & 0.85 & 132 & 1.6 \\
\hline 330 & 47 & 0.96 & 130 & 1.6 \\
\hline 350 & 47 & 0.96 & 130 & 1.6 \\
\hline 340 & 43 & 1.04 & 132 & 1.6 \\
\hline 330 & 41 & 1.09 & 129 & 1.6 \\
\hline
\end{tabular}

Table 4. The results of the experimental study.

\begin{tabular}{|c|c|c|c|}
\hline \multirow{2}{*}{ Parameter } & \multicolumn{3}{|c|}{ Value } \\
\cline { 2 - 4 } & Quartzites & $\begin{array}{c}\text { Magnetite- } \\
\text { amphiboles }\end{array}$ & $\begin{array}{c}\text { Magnetite- } \\
\text { amphibole-silicates }\end{array}$ \\
\hline Plasmatron power, $\mathrm{kW}$ & $170-175$ & $150-160$ & 150 \\
\hline Initial borehole diameter, mm & \multicolumn{3}{|c|}{105} \\
\hline Borehole diameter after reaming, mm & $450-500$ & $270-320$ & $230-250$ \\
\hline $\begin{array}{c}\text { Velocity of the plasmatron nozzle in a } \\
\text { borehole, } \mathrm{m} / \mathrm{hr}\end{array}$ & 1.0 & 1.0 & 0.7 \\
\hline $\begin{array}{c}\text { Initial temperature of the heat transfer } \\
\text { medium, }{ }^{\circ} \mathrm{C}\end{array}$ & No data & No data & $950-1000$ \\
\hline $\begin{array}{c}\text { Initial specific heat flux from the heat } \\
\text { transfer medium to the rock surface, } \\
\mathrm{W} / \mathrm{m}^{2}\end{array}$ & No data & No data & $(8.4-9.5) \cdot 10^{5}$ \\
\hline
\end{tabular}

During the study of the thermal reaming process it was determined that micro cracks appearance occurs when heating temperature of the fine-grained hard rocks reaches 700$800{ }^{\circ} \mathrm{C}$ while for the large-grained hard rocks the heating temperature should be within the range $500-600{ }^{\circ} \mathrm{C}$.

Micro cracks destruct the layer heated up to the temperature of destruction. If the thickness of the heated layer becomes larger than the grains size spalls tend to detach.

Thus, disseminated rocks are subjected to destruction at the temperature $700-900{ }^{\circ} \mathrm{C}$ into the thin spalls during rapid heating (1-2 s). Coarsely disseminated rocks are subjected to destruction at the lower temperature values into the thicker spalls and it takes larger time period.

Comparison of the technological parameters of the hard rock thermal reaming process $(f=16-20)$ is shown in the Table 5 [29].

Parameters of the tests of the borehole thermal reaming by means of supersonic flame jet are shown in the Table 6.

\section{Methods}

In experimental study of the borehole thermal reaming by means of an angular plasmatron energy efficiency of the rock spallation process in comparison to that process operated by mean of axial plasmatron was investigated.

Experimental pattern for the thermal reaming of the borehole within the granite block by means of tangential plasma jets is shown in Figure 1. 
Table 5. Comparison of the technological parameters of the hard rock thermal reaming process.

\begin{tabular}{|c|c|c|c|c|}
\hline Drilling type & $\begin{array}{c}\text { Overall } \\
\text { power, } \mathrm{kW}\end{array}$ & $\begin{array}{c}\text { Borehole } \\
\text { diameter, } \mathrm{mm}\end{array}$ & $\begin{array}{c}\text { Specific power, } \\
\mathrm{kW} \cdot \mathrm{hr} / \mathrm{dm}^{3}\end{array}$ & $\begin{array}{c}\text { Volumetric } \\
\text { productivity, } \\
\mathrm{dm}^{3} / \mathrm{hr}\end{array}$ \\
\hline $\begin{array}{c}\text { Roller-bit } \\
\text { drilling }\end{array}$ & 386 & 250 & 1.57 & 245.4 \\
\hline $\begin{array}{c}\text { Flame jet } \\
\text { drilling } \\
\text { (oxygen) }\end{array}$ & 700 & $180-220$ & $1.5-3.4$ & $204-456$ \\
\hline $\begin{array}{c}\text { Flame jet } \\
\text { reaming (air) }\end{array}$ & 1000 & $400-500$ & 0.7 & $1256-1964$ \\
\hline $\begin{array}{c}\text { Flame jet } \\
\text { drilling (air) }\end{array}$ & 1000 & 200 & $5-6$ & $200-220$ \\
\hline
\end{tabular}

Table 6. Parameters of the tests of the borehole thermal reaming by means of supersonic flame jet.

\begin{tabular}{|c|c|c|c|c|}
\hline \multicolumn{2}{|c|}{ Parameter } & Units & TBV -1000 & TBV -1500 \\
\hline \multicolumn{2}{|c|}{ Initial borehole diameter } & $\mathrm{mm}$ & 250 & 220 \\
\hline \multicolumn{2}{|c|}{ Diameter of the reamed borehole } & $\mathrm{mm}$ & $320-440$ & $360-500$ \\
\hline \multicolumn{2}{|c|}{ Borehole depth } & $\mathrm{m}$ & 19 & 19 \\
\hline \multirow{2}{*}{ Consumption } & kerosene & $\mathrm{m}^{3} / \mathrm{hr}$ & 1920 & 2458 \\
\hline & water & $\mathrm{kg} / \mathrm{hr}$ & 100 & 130 \\
\hline \multicolumn{2}{|c|}{ Jet temperature } & ${ }^{\circ} \mathrm{C}$ & 1100 & 1450 \\
\hline \multicolumn{2}{|c|}{ Average reaming productivity } & $\mathrm{dm}^{3} / \mathrm{hr}$ & 500 & 900 \\
\hline
\end{tabular}

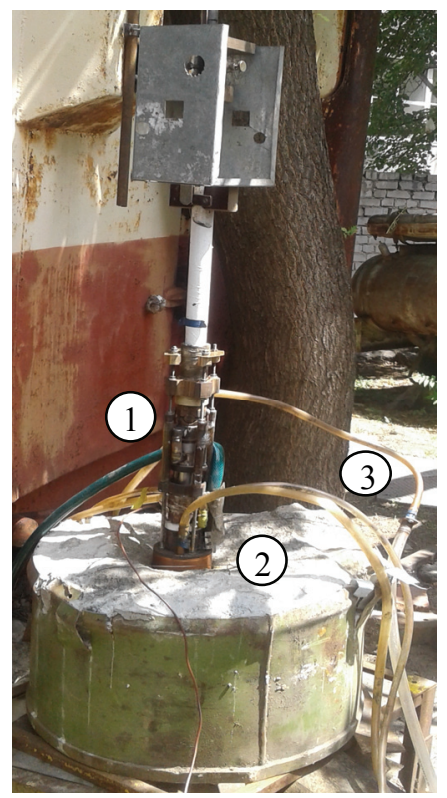

Fig. 1. Experimental set up for the study of the borehole thermal reaming process in the granite block by means of angular plasmatron: 1- plasmatron; 2- granite block; 3- cooling system of the plasmatron.

The angular plasmatron operates as follows: plasmatron attached to the cable drops down into the borehole as well as cooling water supplies cooling channels 3 of the plasmatron, after that plasma forming gas supplies system of the channels 7 . Then electric power source switches on that causes anode assembly 1 and cathode assembly 2 are 
subjected to the no-load voltage. After the plasmatron starts up plasma forming gas that supplies annular channel 6 into the arc zone transforms into plasma and through the plasma forming channels 4 as well as the plasma jets forming channels 5 flows out from the channels 5 as the swirling plasma jets influencing on the borehole surface.

In experimental study vertical axes of the plasmatron 1 as well as inlet orifice of the borehole in the granite block 2 were matched. After the granite spallation spalls were moving straight through to the tin pipe 3 , into the box 4 by means of plasma flow (Fig. 2).

After the switching off the plasmatron blowing of the air through the tin pipe was performed. Then weighting of the spalls was carried out (Fig. 3) by means of VT-200 analytical balance. Accuracy class 4 . Measurement accuracy $\pm 10 \mathrm{mg}$.

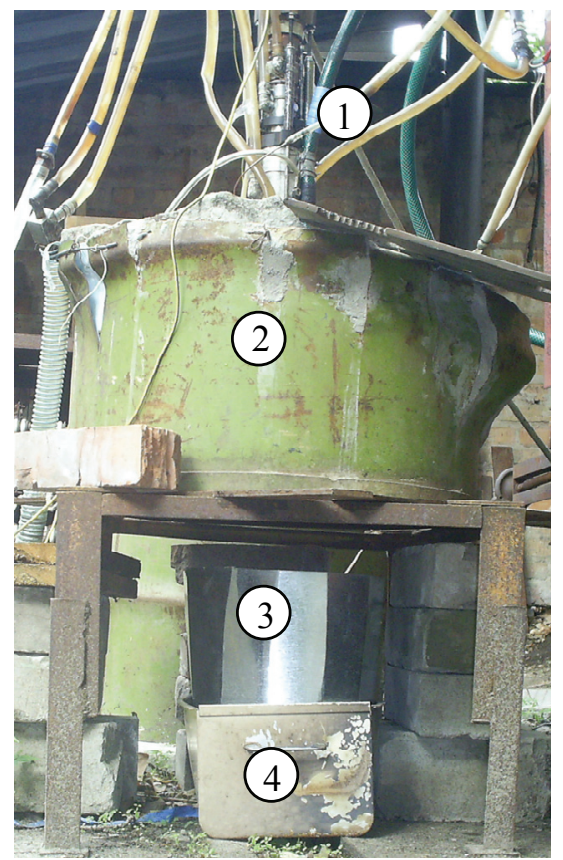

Fig. 2. Devices for the transportation of spalls to the box: 1- plasmatron; 2- granite block; 3- tin pipe for spalls transportation; 4- box for spalls accumulation.

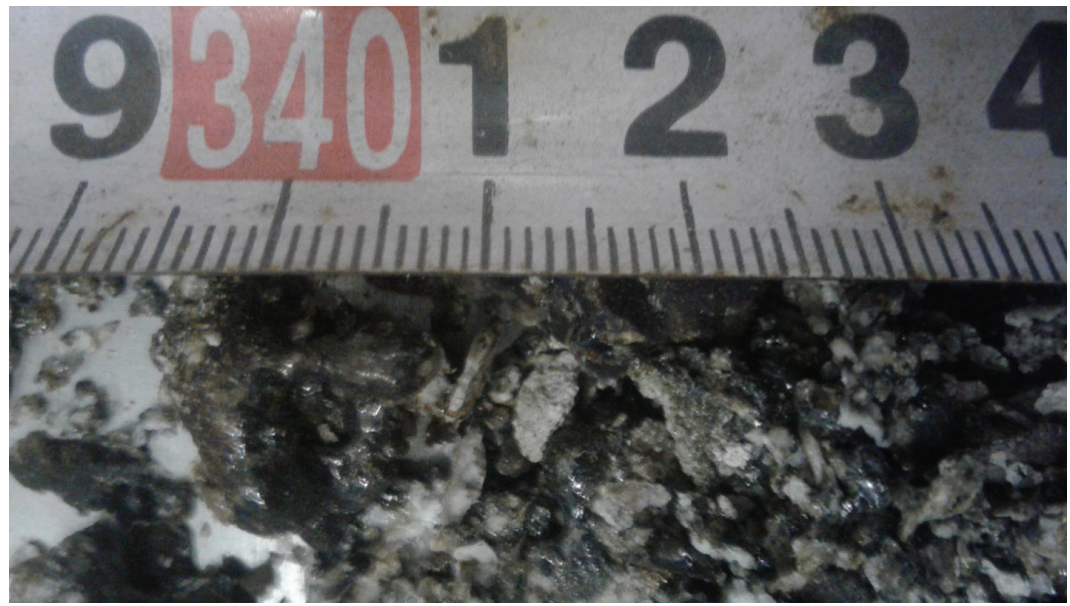

Fig. 3. Spalls of rock after the thermal reaming of the borehole by means of the angular plasmatron. 
Initial temperature of the granite block was within $18-20{ }^{\circ} \mathrm{C}$. Initial diameter of the borehole was $105 \mathrm{~mm}$. Borehole depth was $300 \mathrm{~mm}$.

Main feature of the experimental study is determination of weight of the spalls for the calculation of the energy efficiency of the spallation process.

The values of parameters for the experimental study of the borehole thermal reaming by means of the angular plasmatron are shown in the Table 7.

Table 7. Parameters of the experimental study of the thermal reaming of the borehole by means of the angular plasmatron.

\begin{tabular}{|c|c|c|c|c|c|c|c|}
\hline \multirow{2}{*}{ Parameter } & \multicolumn{7}{|c|}{ Experiment } \\
\cline { 2 - 8 } & $\# 1$ & $\# 2$ & $\# 3$ & $\# 4$ & $\# 5$ & $\# 6$ & $\# 7$ \\
\hline $\begin{array}{c}\text { Operating time of the } \\
\text { plasmatron } \tau, \mathrm{s}\end{array}$ & 12 & 22 & 23 & 24 & 26 & 29 & 35 \\
\hline Plasmatron power, $\mathrm{kW}$ & 57.6 & 52.5 & 50.0 & 54.6 & 50.0 & 57.75 & 57.0 \\
\hline $\begin{array}{c}\text { Energy of the plasma } \\
\text { per experiment, kJ }\end{array}$ & 691.2 & 1211.5 & 1194.7 & 1310.4 & 1406.8 & 1674.8 & 1995 \\
\hline Spalls weight, kg & 0.007 & 0.013 & 0.0131 & 0.016 & 0.0143 & 0.028 & 0.028 \\
\hline $\begin{array}{c}\text { Energy efficiency of the } \\
\text { thermal reaming process } \\
e, \mathrm{~kJ} / \mathrm{g}\end{array}$ & 98.7 & 93.2 & 91.2 & 81.9 & 98.4 & 59.7 & 71.2 \\
\hline $\begin{array}{c}\text { Productivity of the } \\
\text { thermal reaming } \\
\text { process, g/s }\end{array}$ & 0.583 & 0.560 & 0.569 & 0.667 & 0.511 & 0.967 & 0.801 \\
\hline
\end{tabular}

The geometrical parameters of the borehole and the nozzles of the angular plasmatron are adopted in accordance with geometrical similarity to the technological and processing parameters of the plasmatron and diameter of boreholes before the beginning of the thermal reaming process.

\section{Results and discussion}

In Figure 4 comparison of energy efficiency of the thermal reaming process of the borehole of proper and other experimental research is shown [29].

Analysis of Figure 4 allows to make a conclusions as follows:

- increasing of the plasmatron operation time, i.e. duration of the thermal reaming process, leads to the prompt decreasing of the energy efficiency of the process; in particular, reaching of the thermal efficiency range of $0.97-4.48 \mathrm{MJ} / \mathrm{kg}$, that was mentioned in the reference [29], possible for process duration that exceeds $55 \mathrm{~s}$, namely from $55 \mathrm{~s}$ up to $70 \mathrm{~s}$ for plasmatron thermal power within the range $52.0-57.75 \mathrm{~kW}$, that is quite comparable with experimental study [29], where for plasmatron thermal power of $100 \mathrm{~kW}$ energy efficiency of the thermal reaming process reaches the range $0.97-4.48 \mathrm{MJ} / \mathrm{kg}$ while process duration is $100 \mathrm{~s}$.

Thus, time range for spallation energy efficiency within the range $0.97-4.48 \mathrm{MJ} / \mathrm{kg}$ for hardness coefficient range of $f=8-12$ and plasma thermal power $52-57.75 \mathrm{~kW}$ is obtained.

In the Table 8 comparison of the parameters of the borehole thermal reaming by means of the axial and angular plasmatrons is shown.

Table 8 shows that for equal values of the plasma thermal values as well as the energy efficiency of the spallation process application of the angular plasmatron allows to decrease spallation time that, in turn, leads to the increasing of the thermal reaming productivity. 


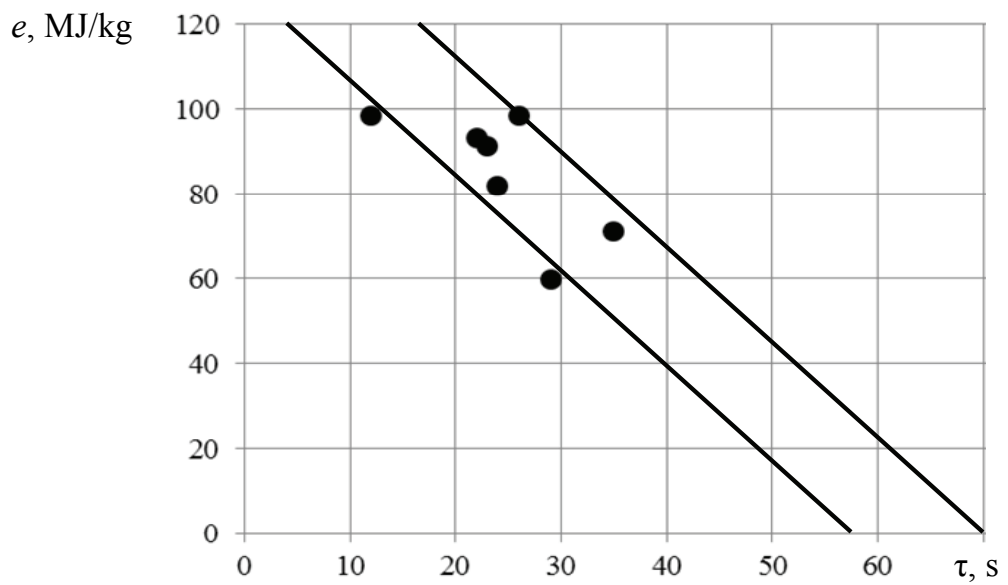

Fig. 4. Influence of the duration of the borehole surface heating on the energy efficiency of the thermal reaming by means of the angular plasmatron.

Table 8. Comparison of the parameters of the borehole thermal reaming by means of the axial and angular plasmatrons.

\begin{tabular}{|c|c|c|c|}
\hline \multirow{2}{*}{$\begin{array}{c}\text { Plasmatron } \\
\text { type }\end{array}$} & $\begin{array}{c}\text { Plasma thermal } \\
\text { power, } \mathrm{kW}\end{array}$ & $\begin{array}{c}\text { Energy efficiency } \\
\text { of the thermal } \\
\text { reaming process } \\
e, \mathrm{MJ} / \mathrm{kg}\end{array}$ & $\begin{array}{c}\text { Time range for spallation } \\
\text { energy efficiency reaching } \\
\tau, \mathrm{s}\end{array}$ \\
\hline Axial & $52.2-57.3$ & $0.97-4.48$ & $90-170$ \\
\hline Angular & $52.0-57.75$ & $0.97-4.48$ & $55-70$ \\
\hline
\end{tabular}

\section{Conclusions}

Time range for spallation energy efficiency within the range $0.97-4.48 \mathrm{MJ} / \mathrm{kg}$ for hardness coefficient range of $f=8-12$ and plasma thermal power $52.0-57.75 \mathrm{~kW}$ is obtained.

For equal values of the plasma thermal values as well as the energy efficiency of the spallation process application of the angular plasmatron allows to decrease spallation time that, in turn, leads to the increasing of the thermal reaming productivity.

\section{References}

1. M. Bazargan, A. Gudmundsson, P. Meredith, J. Browning, N. Inskip, 49-th US Rock Mechanics, Geomechanics Symposium (2015)

2. D. Brkic, M. Kant, T. Meier, M. Schuler, R. von Rohr, World Geothermal Congress (2015)

3. T. Meier, D. May, P. von Rohr, Journal of Thermal Stresses 39, 9 (2016)

4. S. Walsh, I. Lomov, International Journal of Heat and Mass Transfer 65 (2013)

5. R. Potter, J. Potter, T. Wideman, Geothermal Resources Council Transactions 34 (2010)

6. R. Stacey, S. Sanyal, J. Potter, T. Wideman, Geothermal Resources Council Transactions 35 (2011)

7. T. Wideman, N. Sazdanoff, J. Unzelman-Langsdorf, J. Potter, Geothermal Resources Council Transactions 35 (2011)

8. A.Yu. Dreus, K.Ye. Lysenko, Naukovyi visnyk Natsionalnoho Hirnychoho 
Universytetu 5 (2016)

9. R. Wu, M. Osawa, T. Yokokawa, K. Kawagishi, H. Harada, Journal of Solid Mechanics and Materials Engineering 4, 2 (2010)

10. D. Renusch, M. Rudolphi, M. Schütze, Journal of Solid Mechanics and Materials Engineering 4, 2 (2010)

11. M. Yao, Y. He, W. Zhang, W. Gao, Materials Transactions 46, 9 (2005)

12. H. Kihara, M. Hatano, N. Nakiyama, K. Abe, M. Nishida, Transactions of the Japan Society for Aeronautical and Space Sciences 49, 164 (2006)

13. Dmitriev, A.P., Goncharov, S.A., Zilbershmidt, M.G. (2011). Contemporary problems of selective and energy saving rock destruction. Gornyy informatsionno-analiticheskiy byulleten, 1, 169-184

14. Zelenskiy, N.M., (1969). About effectiveness and the prospects of development of thermomechanical rock breaking machines. In: Thermomechanical methods of rock destruction, 32-38

15. Alymov, B.D., Poluyanskiy, S.A., Andreev, A.F., Lebedev, V.Ya., Truskov, I.V., Storozhuk, N.M., (1969). Integrated researches of plasma generators as effective facilities of thermal impact on rocks in thermomechanical rock breaking elements of heading machines. In: Thermomechanical methods of rock destruction, 225-229

16. Dmitriev, A.P., Goncharov, S.A. (1990). Thermodynamical processes in the rocks. Moskva: Nedra

17. O. Voloshyn, I. Potapchuk, O. Zhevzhyk, Naukovyi Visnyk Natsionalnoho Hirnychoho Universytetu 164, 2 (2018)

18. O. Voloshyn, I. Potapchuk, O. Zhevzhyk, V.Yemelianenko, M. Zhovtonoha, M. Sekar, N. Dhunnoo, Mining of Mineral Deposits 13, 1 (2019)

19. Koshelev, K.V., Tomasov, A.G., Samoylov, V.L. (1984). Drifting and maintenance experience of mine workings. Sbornik nauchno-issledovatelskikh rabot Ostravskogo gorno-metallurgicheskogo institute. Seriya Gorno-geologicheskaya, 2, 21-52

20. Epshtein, E.F. (1969). New methods of rock destruction and their development prospects. In: Thermomechanical methods of rock destruction, 25-31

21. Dolgopolov, A.V., Truskov, I.V., Andreev, I.F., Alymov, B.D., Kobozev, V.N., Vekhtev, V.E., Storozhuk, N.M. (1969). Substantiation and test of rational designs of thermomechanical rock breaking elements for heading machines and feature of their operation in narrow slot faces. In: Thermomechanical methods of rock destruction, 110113

22. Moskalyev, A.N., Pigida, E.Yu., Alymov, B.D., Ignatovich, Yu.M., Bura, G.G. (1969). Influence of thermal impact on mineral composition, structural-textural features, phase changes and microhardness of the rocks. In: Thermomechanical methods of rock destruction, $55-58$

23. Zholnach, V.I., Dydzinskiy, V.V., Slipchenko, V.V. (1972). Study of the thermomechanical destruction process of the hard rocks in an annular face. In: Thermomechanical methods of rock destruction. Processes and technical equipment of thermomechanical rock destruction, 50-52

24. Lebedev, V.Ya., Alymov, B.D. (1972). About a possibility of sprung slim holes plasma drilling for underground conditions. In: Thermomechanical methods of rock destruction. Thermal destruction of the rocks by fire flow, 45-48

25. Alymov, B.D., Lebedev, V.Ya., Trofimov, Yu.E. (1976). Electric arc generator for thermomechanical operational element of the heading machine. In: Thermomechanical methods of rock destruction, 116-117

26. Kasyanov, V.E., Musolin, V.N., Snegov, A.I. (1976). Plasma rock breaking elements. In: Thermomechanical methods of rock destruction, 157-158

27. Kholyavchenko, L.T., Osenniy, V.Ya. (1995). Technology and equipment of the 
borehole plasma reaming for mining enterprises. Plazmotekhnologiya-95: sbornik nauchnykh trudov, 221-224

28. Osenniy, V.Ya. (1997). Investigation results of the thermal reaming of the boreholes in a hard rocks. Plazmotekhnologiya-97: sbornik nauchnykh trudov, 229-232

29. Zhukov, S.O., Sorokopud, A.V. (2001). Efficiency augmentation of the combined method of the boreholes drifting. Visnyk ZhITI. Seriya Tekhnichni nauky, 17, 106-110 